\title{
Optical Microscopy as a Tool to Correlate Morphology and Thermal Properties of Extruded PET/PC Reactive Blends
}

\author{
Luis Claudio Mendes*, Patricia Soares da Costa Pereira
}

Instituto de Macromoléculas Professora Eloisa Mano-IMA, Universidade Federal do, Rio de Janeiro-UFRJ, Centro de Tecnologia, Bloco J, Avenida Horácio, Macedo, Rio de Janeiro, RJ, Brasil.

Email: *1cmendes@ima.ufrj.br

Received May $16^{\text {th }}, 2011$; revised June $20^{\text {th }}, 2011$; accepted June $30^{\text {th }}, 2011$.

\begin{abstract}
Catalysed and uncatalysed reactive extruded poly(ethylene terephthalate)/poly(bisphenol-A carbonate) (PET/PC) blends phase structure at compositional range containing 0 - $100 \mathrm{wt} \%$ of both parent polymers were evaluated. Phase separation was supported by TG/DTG, DMA and DSC. The changes on $T_{g}$ and $T_{m}$ of the parent polymers were associated to the esterification and transesterification reactions inside the phases and into the interfacial region. According to optical observations, not yet published in this matter, the blend morphology was dictated, either composition or melt flow rate and in the whole composition range, a matrix-droplet morphology was noticed. PET was only able to be crystallized in blends in which it was the matrix. Mostly, the PET/PC blends revealed to be partially miscible systems in which the level of the transesterification/esterification reactions was driven by the kind of matrix. The latter showed great influence on the thermal properties.
\end{abstract}

Keywords: PET/PC, Phase Structure, Morphology, OM, DMA, DSC, TG/DTG

\section{Introduction}

It is well known the qualities and significance of poly (ethylene terephthalate) (PET) and poly (bisphenol-A polycarbonate) (PC) as commodities and engineering plastics. In order to gather their individual characteristics to yield a new material, their blends have been studied for at least a quarter of century. Jointly, chemical similarity, capacity of reacting to each other in the molten state and fairly easy processing among others have been attractive to encourage their blends investigation. When dealing with reactive processing, Utracki [1] underlined that to ascertain the renewal of the interface, ability to react across the interface, sufficient reaction rate and as well the stability of both the formed chemical structures and morphology are vital conditions for its success. The expected miscibility due to the occurrence of esterification and transesterification reactions during the mechanical blending has been an object of discussion. The discrepances could be attributed to many factors - molar mass, melt flow rate (MFR), intrinsic viscosity, end groups content of the homopolymers; temperature, pressure, screw profile, res- idence time of processing; absence and presence of catalyst-for instance. In recent work, Al-Jabareen et al. [2] investigated reactive extruded PC/PET blendsonly PC rich blends, with/without different transesterification catalysts and with the addition of Irganox as heat stabilizer. Even considering that the blends were processed twice in different extruders and that also two screw speeds were also applied, it was found that all blends are formed by a PC matrix and PET dispersed phase. Hay and co-authors [3] prepared PET/PC blends-PC content $10-50 \mathrm{wt} \%$, without and with lanthanum acetylacetonate, at utmost extrusion temperature. The blends were considered completely immiscible over the composition range studied. The relationship between miscibility and chemical structures of PET-PC uncatalysed reactive blend prepared by melt mixing, for prolonged time, was assessed by Zhang and collaborators [4]. With increasing reaction time, they detected the progressive enhance of the miscibility until a single $\mathrm{Tg}$ has been reached. Melt mixing PET/PC blends have been yielded by Marchese et al. [5] taking into account distinguished PET molar mass, the pres- 
ence of different residual catalysts in PET and as well distinct mixing times. They pointed out that the presence of single or two Tgs were dependent on the molecular mass of the PET blocks, considering that the PET and PC crystallizations were possible due to the chain rearrangements and block length. An article on reactive extruded PET/PC blends in which PET waste from recycled bottles was blended with virgin PC, without/with catalysts, in a whole range of composition was published by Carrot and coworkers [6]. Their rheological and SEM observations showed the occurrence of matrixdroplet morphology for all compositions and a phase inversion point for PET/PC 50/50 wt $\%$ blend. Stannous octoate was tested as a transesterification inducer in reactive extruded PET/PC blends in a wide range of composition. According to the authors, it was found two distinct glass transitions in all cases confirming that the polymers are not miscible even in the presence of catalyst [7]. A study on the efficiency of different transesterification catalysts on phase behavior of PET/PC blend (50/50 wt\%), by melt mixing at prolonged reaction times was performed. A single $\mathrm{Tg}$ was observed when the block copolymer length had reached fifteen monomeric units [8]. Some articles have been published by Mendes and his group [9-12]. Latterly, two works on rheological study and effectiveness of catalyst on PET/PC reactive extruded blends were issued. They evidenced the significance of the matrix for driving the interchange reactions and the efficiency of the catalyst as a real tranesterification promoter [13]. In the present work, we tried to correlate the morphology and thermal properties of the PET/PC reactive extruded blends taking into consideration the importance of the blend matrix based on the progress of the esterification and transesterification reactions.

\section{Experimental}

\subsection{Materials}

PET and PC manufacturers as well as their characteristics were displayed in Table 1. Commercial cobalt acetylacetonate produced by J. T. Baker Chemical Co. was used as catalyst.

\subsection{Blending}

The reactive blend was processed in a co-rotating twin-screw extruder $(\mathrm{L} / \mathrm{D}=36$, screw diameter $=22$ $\mathrm{mm}$ ), equipped with vacuum system, at temperature range of $190-255^{\circ} \mathrm{C}$ and speed of $150 \mathrm{rpm}$. The blend compositional range covered $0,20,50$ and $100 \mathrm{wt} \%$ of each polymer, with $(500 \mathrm{ppm})$ and without cobalt acetylacetonate II, a transesterification catalyst. Previously, a master of PET/catalyst was extruded for preparing catalysed blend. Prior to blending, the polymers were dried at $120^{\circ} \mathrm{C}$, during 8 hours.

\subsection{Thermogravimetry/thermogravimetry Derivative (TG/DTG)}

The thermal behavior of the blends were taken from TG/DTG curves using a TA thermogravimetric analyser model Q 500, in the temperature range of $30-700^{\circ} \mathrm{C}$, at $10^{\circ} \mathrm{C} \cdot \mathrm{min}^{-1}$, under nitrogen atmosphere. The onset, maximum degradation and end temperatures, respectively, $T_{\text {onset }}, T_{\max }, T_{\text {end }}$ and residue contents were determined.

\subsection{Differential Scanning Calorimeter (DSC)}

A TA calorimeter model Q1000 was used to register the calorimetric events in the heating and cooling regimes. The first regime of heating was performed from 40 to $300^{\circ} \mathrm{C}$ at heating rate of $10^{\circ} \mathrm{C} \cdot \mathrm{min}^{-1}$, under nitrogen atmosphere, kept for 2 min for eliminating the thermal hystory. After that, the first regime of cooling was applied up to $40^{\circ} \mathrm{C}$ at maximum rate. The second regime of heating followed the same temperature range and rate of the first one. Finally, the second regime of cooling was conducted until $40^{\circ} \mathrm{C}$ at rate of $10^{\circ} \mathrm{C} \cdot \mathrm{min}^{-1}$. The glass transition, crystallization, melting temperatures, respectively $\left(T_{g}\right),\left(T_{c}\right),\left(T_{m}\right)$ and enthalpy of fusion $\left(\Delta H_{m}\right)$ were measured. The heating and cooling crystallization temperatures, $\mathrm{T}_{\mathrm{ch}}$ and $\mathrm{T}_{\mathrm{cc}}$, were determined when it was possible. The PET's degree of crystallization $\left(\mathrm{X}_{\mathrm{c}}\right)$ was calculated from the ratio of PET endothermic peak area $\left(\Delta \mathrm{H}_{\mathrm{m}}\right)$ and the enthalpy of fusion of $100 \%$ crystalline PET $\left(136 \mathrm{~J} \cdot \mathrm{g}^{-1}\right)$.

\subsection{Dynamic-Mechanical Analysis (DMA)}

A dynamic-mechanical analyser from TA equipment

Table 1. Polymers origin and characteristics.

\begin{tabular}{cccc}
\hline Polymer & Density $\left(\mathrm{g} . \mathrm{cm}^{-3}\right)$ & Melt flow rate $\left(\mathrm{g} .10 \mathrm{~min}^{-1}\right)$ & Manufacturer \\
\hline PET & 1.39 & 33.0 & Mossi \& Ghisolfi Group \\
PC & 1.20 & 2.5 & GE Plastics South America \\
\hline
\end{tabular}


model DMA-298 allowed to assess the Tan $\delta$ using rectangular specimens of $40 \times 10 \times 0.5 \mathrm{~mm}$ in the following experimental conditions: bending mode, $1 \mathrm{~Hz}$, temperature range $50-170^{\circ} \mathrm{C}$ and heating rate of $2^{\circ} \mathrm{C} \cdot \mathrm{min}^{-1}$.

\subsection{Morphological Analysis}

The blend morphology was featured through a Zeiss microscopy model THMS 600 from squeezed film between two microscope glass slices. The assembly was inserted into the microscope hot stage and heated from 25 to $280^{\circ} \mathrm{C}$ where was kept for 2 minutes in order to eliminate the thermal history. After that, the cooling was performed until $25^{\circ} \mathrm{C}$. The phase separation and the crystallization process were monitored by taking photographs.

\section{Results and Discussion}

\subsection{Thermogravimetry/thermogravimetry Derivative (TG/DTG)}

TG/DTG curves and $T_{\text {onset, }}, T_{\max }, T_{\text {end }}$, residue content are arranged in Figures 1-4 and Table 2, respectively. The homopolymers degraded at a single step, whereas the blends into two ones for both kinds of blends. The latter showed the $\mathrm{T}_{\text {onset }}$ values below to the PET homopolymer. The DTG curves showed two peaks of degradation in which the first one was correlated with the PET-rich phase while the second one with the PC-rich one. It is worth observing that the derivative weight peak intensity changed with the composition for the uncatalysed blends

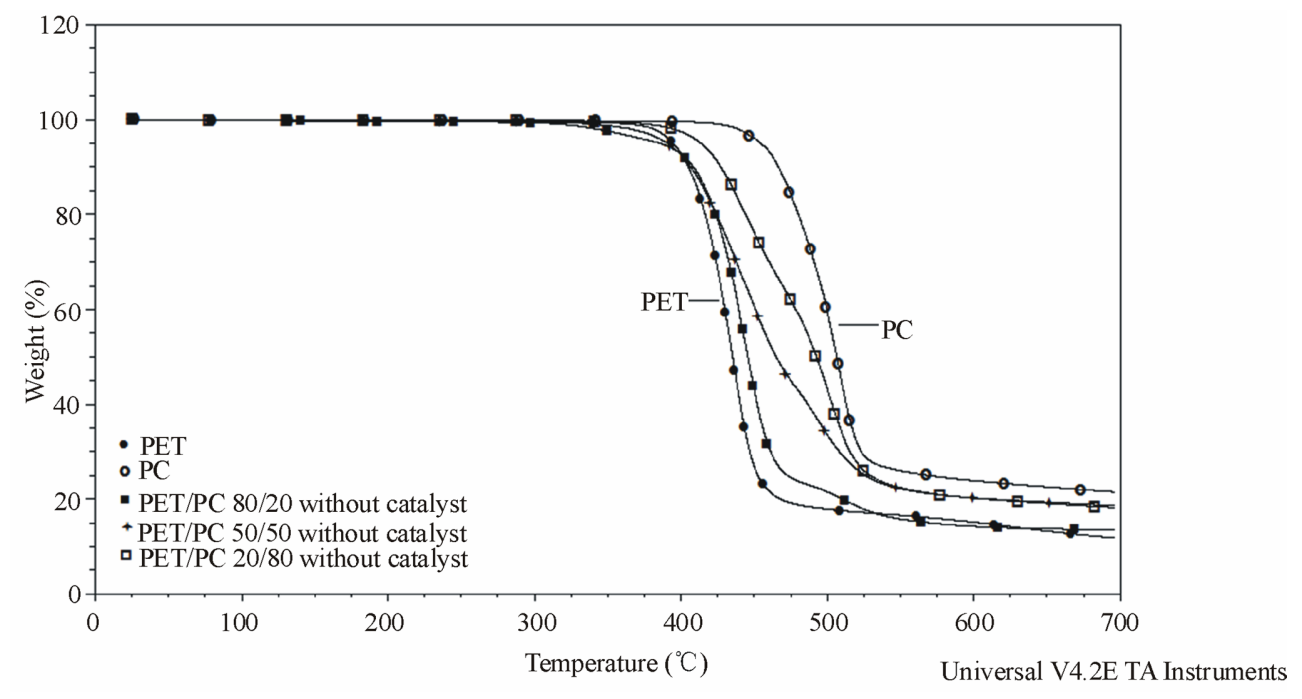

Figure 1. TG without catalyst.

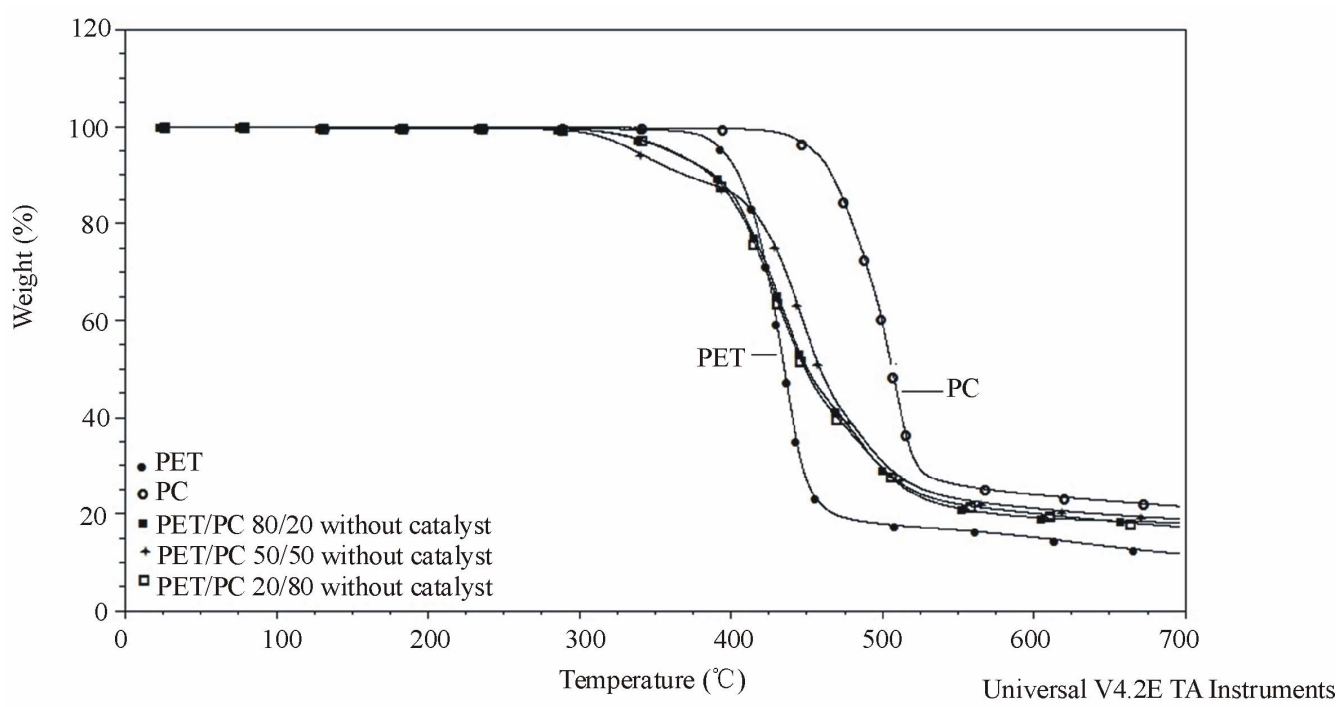

Figure 2. TG with catalyst. 


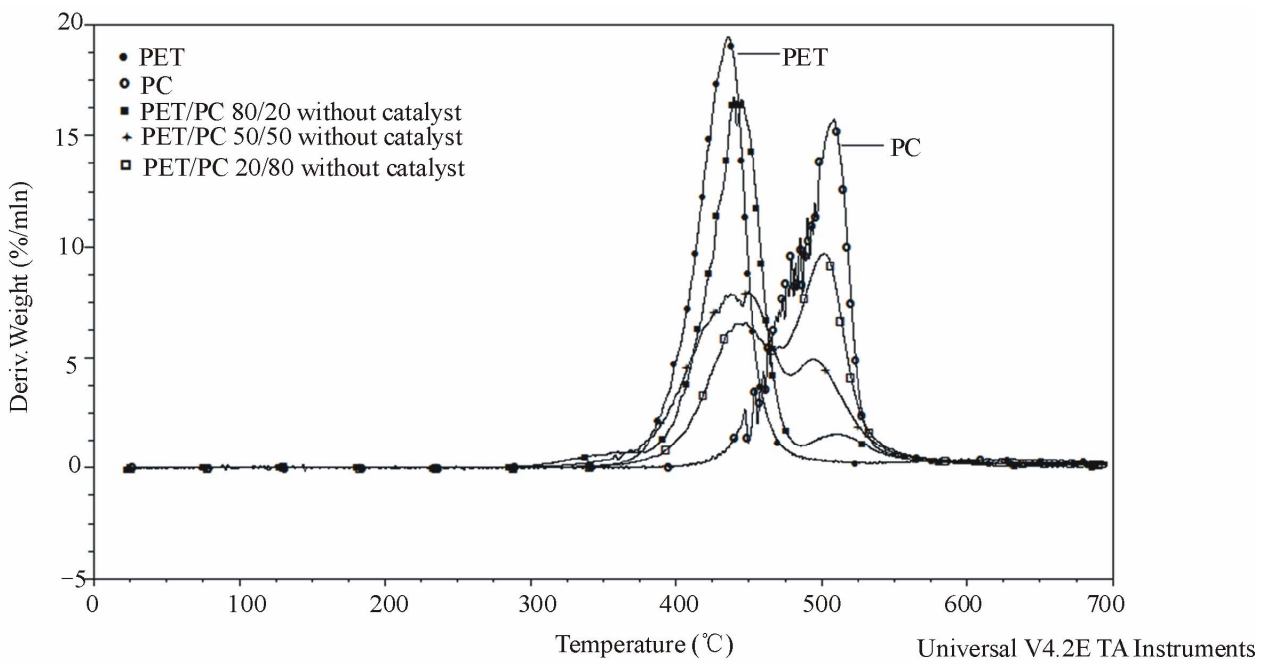

Figure 3. DTG without catalyst.

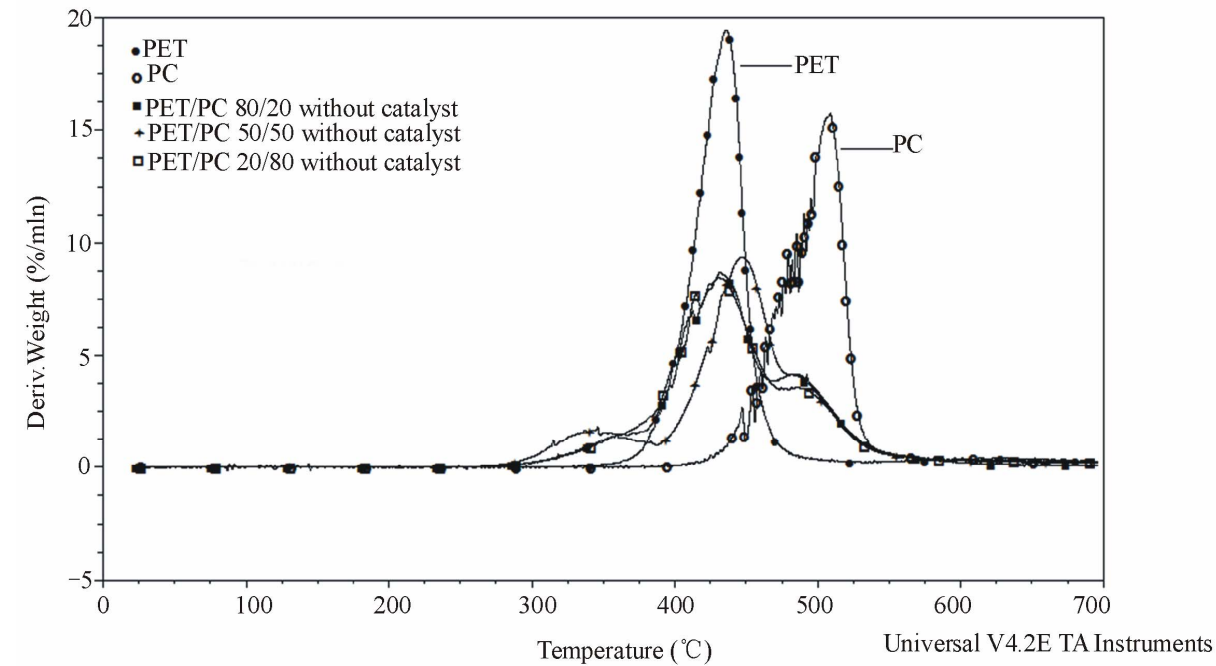

Figure 4. DTG with catalyst.

Table 2. TG/DTG parameters for PET, PC and blends.

\begin{tabular}{|c|c|c|c|c|c|}
\hline \multirow[b]{2}{*}{ Sample } & \multicolumn{2}{|c|}{ Degradation temperature $\left({ }^{\circ} \mathrm{C}\right)$} & \multirow{2}{*}{$\begin{array}{c}\text { Residue content } \\
(\%)\end{array}$} & \multicolumn{2}{|c|}{$\mathrm{T}_{\max }$} \\
\hline & $\mathrm{T}_{\text {onset }}$ & $\mathrm{T}_{\text {end }}$ & & PET-rich phase & PC-rich phase \\
\hline PET & 375 & 465 & 12 & 436 & - \\
\hline PC & 460 & 525 & 23 & - & 508 \\
\hline $80 / 20^{\mathrm{a}}$ & 318 & 510 & 11 & 443 & 510 \\
\hline $50 / 50^{\mathrm{a}}$ & 320 & 520 & 19 & 445 & 494 \\
\hline $20 / 80^{\mathrm{a}}$ & 322 & 518 & 18 & 445 & 501 \\
\hline $80 / 20^{b}$ & 325 & 519 & 18 & 431 & 483 \\
\hline $50 / 50^{\mathrm{b}}$ & 309 & 517 & 19 & 447 & 485 \\
\hline $20 / 80^{\mathrm{b}}$ & 325 & 515 & 17 & 429 & 486 \\
\hline
\end{tabular}

a- without catalyst; b- with catalyst

but its magnitude is always at higher values for PET-rich phase when the catalysed systems are considered. This could be ascribed to the unlike level of the acidoly- sis/alcoholysis and transesterification reactions in both blends. The percentages of coal residue are between the homopolymers. Herein, the TG/DTG analysis showed 
that both $\mathrm{PET} / \mathrm{PC}$ blends presented at least two phases.

\subsection{Dynamic-Mechanical and Calorimetric Analyses}

Table 3 shows the $T_{g}$ values from DMA for all blends. Most of them were shifted in relation to the parent homopolymers. Meanwhile the $\mathrm{T}_{\mathrm{g}}$ of PE-rich phase displaced to higher temperatures the $T_{g}$ of PC-rich phase showed tendency to diminish, a typical behavior of partially miscible system. The role of the catalyst as transesterification promoter did not change the PET and PC $\mathrm{T}_{\mathrm{g}}$ 's values of the $80 / 20$ blend. Only the PET's $\mathrm{T}_{\mathrm{g}}$ was altered in the blend with equal polymers weight percent. Nevertheless, a single $T_{g}$ was detected in the $20 / 80$ blend. Based on the $T_{g}$ values, it was determined the amount of the polymer/copolymer inside of each phase (Table 4). The catalyst had a remarkable role in blends with 50 and $80 \mathrm{wt} \%$ of PC. In all cases, DMA results pointed out that the PET and PC formed miscible blends partially.

Table 5 shows the $\mathrm{T}_{\mathrm{ch}}, \mathrm{T}_{\mathrm{m}}$ and $\mathrm{X}_{\mathrm{c}}$ for all blends. In both kinds of blends, when detected the $T_{c h}$ was shifted to higher temperatures while the $\mathrm{T}_{\mathrm{m}}$ and $\mathrm{X}_{\mathrm{c}}$ decreased.

The presence of PC low molar mass and PET/PC copolymer inside the PET-rich phase retarded the PET crystallization and were also able to influence the PET crystal size and crystallizablity.

\subsection{Optical Microscopy Analysis}

All blends showed morphology like matrix-droplet in both the molten state and after cooling besides an interfacial region (Figures 5 and 6). The droplets were somewhat distorted due to the coalescent effect with average dimensions in the range of 200-1200 microns. Blend morphology may be influenced by several factors - blend composition, polymers viscosity ratio, interfacial tension, shearing, processing time, among others [14]. For checking which polymer was the matrix or the disperse phase in the blends, the PET crystallization was monitored. In the $80 / 20$ blend, the morphology was driven by compositional effect. As PET crystallization only occurred outside the disperse domains, it was deduced that the matrix was PET. For intermediate composition, polymers viscosity ratio effect predominated to the formation of the blend morphology. The PET crystallization began firstly outside the disperse phase and after few minutes feeble crystals appeared in it. It led to the conclusion that PET was the matrix. In the blend with the highest PC content, the compositional effect was uppermost in blend morphology. Since PET crystals were not observed neither matrix nor disperse phase it was deduced that PC was the matrix. Even in the presence of the cobalt catalyst, the PET/PC blends remained as two phase systems. The observations taken from
Table 3. $T_{g}$ measurements from DMA.

\begin{tabular}{cccc}
\hline \multirow{2}{*}{ Sample } & \multicolumn{2}{c}{$\mathrm{T}_{\mathrm{g}}\left({ }^{\circ} \mathrm{C}\right)$} & \multirow{2}{*}{ Tg FOX $\left({ }^{\circ} \mathrm{C}\right)$} \\
\cline { 2 - 3 } & PET phase & PC phase & - \\
PET & 81 & - & - \\
PC & - & 158 & 95 \\
$80 / 20^{\mathrm{a}}$ & 89 & 147 & 116 \\
$50 / 50^{\mathrm{a}}$ & 94 & 146 & 140 \\
$20 / 80^{\mathrm{a}}$ & 78 & 155 & 95 \\
$80 / 20^{\mathrm{b}}$ & 89 & 148 & 116 \\
$50 / 50^{\mathrm{b}}$ & 107 & 145 & 140 \\
$20 / 80^{\mathrm{b}}$ & - & 140 & \\
\hline a- without catalyst; b- with catalyst & &
\end{tabular}

Table 4. PET and PC content in each phase.

\begin{tabular}{ccc}
\hline PET/PC blend & PC in PET phase $(\%)$ & PET in PC phase $(\%)$ \\
$80 / 20^{\mathrm{a}}$ & 11 & 4 \\
$50 / 50^{\mathrm{a}}$ & 20 & 6 \\
$20 / 80^{\mathrm{a}}$ & $\approx 0$ & 2 \\
$80 / 20^{\mathrm{b}}$ & 11 & 4 \\
$50 / 50^{\mathrm{b}}$ & 35 & 7 \\
$20 / 80^{\mathrm{b}}$ & --- & 12 \\
\hline a- without catalyst; b- with catalyst
\end{tabular}

Table 5. DSC parameters for PET, PC and blends.

\begin{tabular}{cccc}
\hline Sample & $\mathrm{T}_{\mathrm{ch}}\left({ }^{\circ} \mathrm{C}\right)$ & $\mathrm{T}_{\mathrm{m}}\left({ }^{\circ} \mathrm{C}\right)$ & $\mathrm{X}_{\mathrm{c}}\left({ }^{\circ} \mathrm{C}\right)$ \\
PET & 137 & 247 & 20 \\
$\mathrm{PC}$ & - & - & - \\
$80 / 20^{\mathrm{a}}$ & 178 & 234 & 18 \\
$50 / 50^{\mathrm{a}}$ & 172 & 233 & 10 \\
$20 / 80^{\mathrm{a}}$ & - & - & - \\
$80 / 20^{\mathrm{b}}$ & 186 & 229 & 10 \\
$50 / 50^{\mathrm{b}}$ & - & - & - \\
$20 / 80^{\mathrm{b}}$ & - & - & - \\
\hline
\end{tabular}

a- without catalyst; b- with catalyst

optical microscopy may help to understand the ther mal results.

In general, the exchange reactions in the blend of polyesters may proceed by two different mechanisms - esterification and transesterification. The first one takes place by a direct attack of reactive chain outer functional groups (hydroxyl, ester, carboxyl) on inner groups (ester, carbonate). The second mechanism occurs by reactions between inner functional groups (ester and carbonate) situated along the polymer chain. Herein, the parent polymers are high molecular mass materials and it is expected that the number of skeletal ester groups will be higher than the end chain functional ones. Then, it is assumed that transesterification firstly occurs in PET/PC blend.

As the blend is an immiscible system in the molten state, the inner-inner mechanism (Scheme 1-transesterification) operates through the interfacial region. Considering the PET as matrix, there is a sea of PET molecules surrounded by islands of PC. The attack of PET ester-inner groups on 

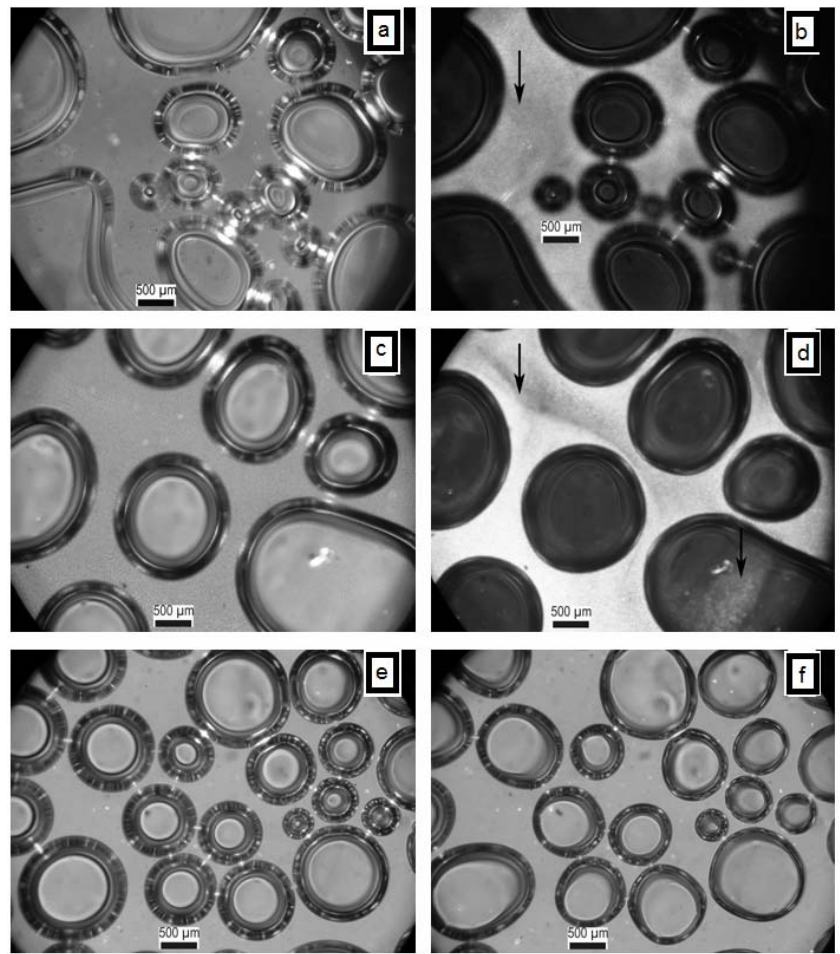

Figure 5. Uncatalysed blends optical photographs: 80/20 (a-molten state; b-solid state), 50/50 (c-molten state; d-solid state), 20/80 (e-molten state; f-solid state).
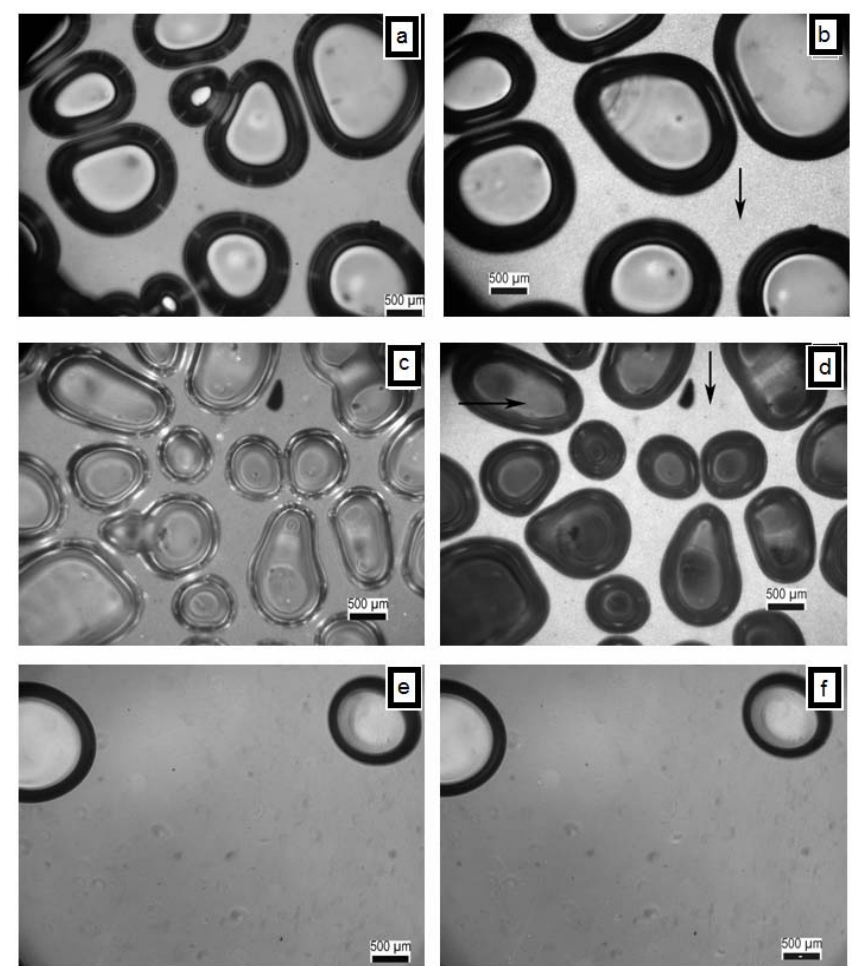

Figure 6. Catalyzed blends optical photographs: 80/20 (a-molten state; b-solid state), 50/50 (c-molten state; d-solid state), 20/80 (e-molten state; f-solid state). 
PC carbonate-inner groups led to the formation of aromatic-aromatic ester copolymer in the interfacial region and the dissolution of the aliphatic-aromatic ester copolymer into the PET-rich phase. Inside the latter, the PC segment inserted along copolymer chain is subjected to transesterification reaction and direct attack of PET reactive chain outer functional groups-hydroxyl and carboxyl-(Scheme 1-acidolysis and alcoholysis). These reactions provided copolymer with PC low chain segments and released PC low molecular mass molecules inside the matrix. These events are dependent on the amount of PC domains and may be interrupted until the access of PET chain to the PC domains is avoided by the presence of the copolymer in the interfacial region. Thus, the highest $\mathrm{T}_{\mathrm{g}}$ value and the amount of PC in PET-rich phase were noticed to the $50 / 50$ blend and partially miscible systems were achieved. Our results differ from those found by Arefazar et al. [15]. They stated that PET/PC mixing blends prepared without catalyst were immiscible.

The kind of matrix seems to influence the occurrence of the transesterification reaction. As can be seen, the glass transition temperatures of PET and PC phases did not change in the blend containing high content of $\mathrm{PC}$ and without catalyst. Although there is a sea of PC molecules in the matrix the energy level necessary for the attack of PC carbonate groups on the PET ester ones seems to be high. Only, in the presence of catalyst the activation energy was enough reduced allowing the occurrence of the transesterification reaction and then, the displacement of $\mathrm{T}_{\mathrm{g}}$ was noticed. Additionally, as stated by Montaudo et al. [16], PC phenol end groups must be considered unreactive which led to conclude that the alcoholysis reaction of the $\mathrm{PC}$ hydroxyl end groups on PET ester linkage in the PC-rich phase could be neglected.

\section{Conclusions}

The relationship between morphology and thermal properties of PET/PC melt mixing blends was investigated. It was observed the interference of the kind of matrix on the transesterification reaction and its consequence on the thermal properties. The catalyst was actually effective in some blends and the systems are partially miscible blends.

\section{Acknowledgements}

The authors thank the Conselho Nacional de Desenvolvimento Científico e Tecnológico (CNPq), Fundação

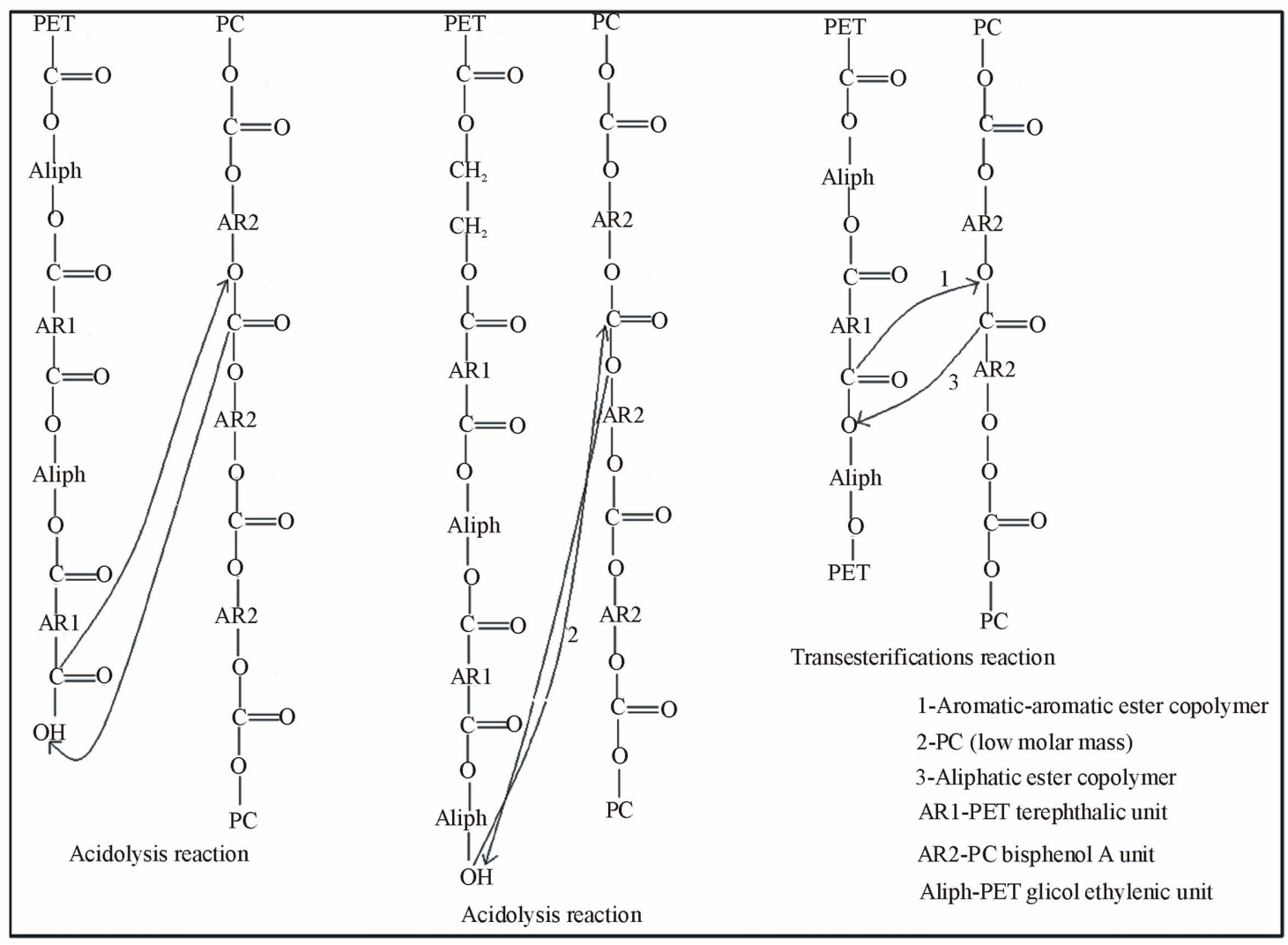

Scheme 1. PET/PC Alcoholysis, acidolysis and transesterification reaction. 
Coordenação do Aperfeiçoamento de Pessoal de Nível Superior (CAPES) and Universidade Federal do Rio de Janeiro (UFRJ) for supporting this investigation.

\section{REFERENCES}

[1] L. A. Utracki, "Compatibilization of Polymer Blends," Canadian Journal of Chemical Engineering, Vol. 80, No. 6, 2002, pp. 1008-1016. doi:10.1002/cjce.5450800601

[2] A. Al-Jabareen, S. Illescas, M. L. I. Maspoch and O. O. Santana, "Effects of Composition and Transesterification Catalysts on the Physico-chemical and Dynamic Properties of PC/PET Blends Rich in PC," Journal of the Materials Science, Vol. 45, No. 24, 2010, pp. 6623-6633. doi:10.1007/s10853-010-4753-4

[3] Y. Kong and J. N. Hay, "Miscibility and Crystallization Behavior of Poly(Ethyelene Terephthatale)/Polycarbonate Blends," Polymer, Vol. 43, No. 6, March 2002, pp. 18051811. doi:10.1016/S0032-3861(01)00772-8

[4] Z, Zhang, Y. Xie and D. Ma, "Relationship between Miscibility and Chemical Strucutures in Reactive Blending of Poly(Bisphenol A Carbonate) and Poly(Ethylene Terephthalate," European Polymer Journal, Vol. 37, No. 10, October 2001, pp. 1961-1966. doi:10.1016/S0014-3057(01)00089-1

[5] P. Marchese, A. Celi, M. Fiorini and M. Gabaldi, "Effects of Annealing on Crystallinity and Phase Behavior of PET/PC Block Copolymers," European Polymer Journal, Vol. 39, No. 6, June 2003, pp. 1081-1089. doi:10.1016/S0014-3057(02)00377-4

[6] C. Carrot, S. Mbarek, M. Jaziri, Y. Chalamet, C. Raveyre and F. Prochazka, "Immiscible Blends of PC and PET, Current Knowledge and New Results: Rheological Properties," Macromolecular Materials Engineering, Vol. 292, No. 6, 2007, pp. 693-706. doi:10.1002/mame.200700006

[7] C. Carrot, S. Mbarek and M. Jaziri, "Recycling Poly(Ethyelene Terephthalate) Wastes: Properties of Poly (Ethylene Terephyhalate)/Polycarbonate Blends and the Effect of a Transesterification Catalyst," Polymer Engineering \& Science, Vol. 46, No. 10, 2006, pp. 1378- 1386. doi:10.1002/pen.20625

[8] P. Marchese, A. Celi and M. Fiorini, "Influence of Activity of Transesterification Catalysts on the Phase Behavior of PC-PET Blends," Macromolecular Chemistry and Physics, Vol. 203, No. 4, 2002, pp. 695-704.
doi:10.1002/1521-3935(20020301)203:4<695::AID-MA CP695>3.0.CO;2-C

[9] L. C. Mendes, A. M. Giornes, A. F. Cordeiro, M. R. Benzi and M. L. Dias, "Miscibility of PET/PC Blends Induced by Cobalt Complexes," International Journal of Polymeric Materials, Vol. 56, No. 3, March 2007, pp. 257-272. doi:10.1080/00914030600812491

[10] P. S. C. Pereira, L. C. Mendes, L. Sirelli and M. L. Dias, "Influence of Cobalt Complex on Thermal Properties of Poly(Ethylene Terephthalate)/Polycarbonate Blend," Journal of Thermal Analysis and Calorimetry, Vol. 87, No. 3, March 2007, pp. 667-671. doi:10.1007/s10973-006-7873-y

[11] P. S. C. Pereira, L. C. Mendes and R. E. R. Abrigo, "Changes in Properties of PET/PC Blend by Catalyst and Time," International Journal of Polymeric Materials, Vol. 57, No. 4-6, 2008, pp. 494-505. doi:10.1080/00914030701816045

[12] L. C. Mendes, R. E. R Abrigo, V. D. Ramos and P. S. C. Pereira, "Effect of Melt Flow Rate of Polycarbonate and Cobalt Catalyst on Properties of PET/PC (80/20 wt\%) Reactive Blending," Journal of Thermal Analysis and Calorimetry, Vol. 99, No. 2, 2009, pp. 545-549. doi:10.1007/s10973-009-0211-4

[13] P. S. C. Pereira, L. C. Mendes and V. D. Ramos, "Rheological Study Bringing New Insights into PET/PC Reactive Blends," Macromolecular Symposia, Vol. 290, No. 1, 2010, pp. 121-131. doi:10.1002/masy.201050414

[14] W. Bu and J. He, "The Effect of Mixing Time on the Morphology of Immiscible Polymer Blends," Journal of Applied Polymer Science, Vol. 62, No. 9, 1996, pp. 14451456.

doi:10.1002/(SICI)1097-4628(19961128)62:9<1445::AID -APP14>3.0.CO;2-Y

[15] P. Zahedi and A. Arefazar, "Blends of Poly(Ethylene Terephthalate)/Polycarbonate by the Use of Lanthanum Acetyl Acetonate Catalyst," Journal of Applied Polymer Science, Vol. 107, No. 5, 2008, pp. 2917-2922. doi:10.1002/app. 27360

[16] G. Montaudo, F. Samperi and C. Puglisi, "Mechanism of Exchange in PBT/PC and PET/PC Blends: Composition of the Copolymer Formed in the Melt Mixing Process," Macromolecules, Vol. 31, No. 3, 1998, pp. 650-661. doi:10.1021/ma9712054 